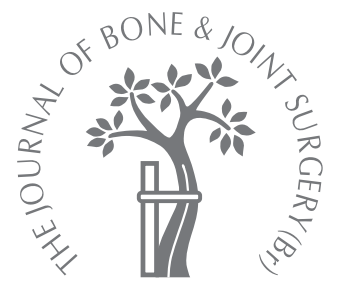

G. Holt,

D. Macdonald,

M. Fraser,

A. T. Reece

From Western

Infirmary, Glasgow, Scotland

\title{
Outcome after surgery for fracture of the hip in patients aged over 95 years
}

Despite the increase in numbers of the extreme elderly, little data is available regarding their outcome after surgery for fracture of the hip. We performed a prospective study of $\mathbf{5 0}$ patients aged 95 years and over who underwent this procedure. Outcome measures included morbidity, mortality, hospital stay, residential and walking status. Comparison was made with a control group of 200 consecutive patients aged less than 95 years who had a similar operation. The mortality at 28 and 120 days was higher $(p=0.005, p=0.001)$ in the patients over 95 years. However, the one-year cumulative post-operative mortality was neither significantly different between the two groups $(p=0.229$ ) nor from the standardised mortality rate for the age-matched population $(p=0.445)$. Predictors of mortality included the ASA grade, the number of comorbid medical conditions and active medical problems on admission. Patients over 95 were unlikely to recover their independence and at a mean follow-up of 29.3 months (12.1 to 48 ) $96 \%$ required permanent institutional care.

More than $60 \%$ of patients with a fracture of the hip have significant coexisting medical problems at the time of presentation, ${ }^{1}$ and a one-year mortality rate of between $14 \%$ and $47 \%$ has been reported. ${ }^{2-12}$ The lifetime incidence of hip fracture in the United Kingdom is approximately $18 \%$ in women and $6 \%$ in men. ${ }^{13}$ The annual incidence increases with age, rising from three per 100 women aged between 65 and 74 to 12.6 per 100 aged 85 or older. ${ }^{14,15}$

At present there are some 250000 people over the age of 95 residing in the United Kingdom and it is predicted that this number will increase dramatically over the next decade. ${ }^{16}$ Previous studies have associated advanced age with increased mortality after hip fracture, ${ }^{17-22}$ and increasing age has been linked with poorer functional recovery, diminished walking ability and increased post-operative complications. ${ }^{6,8,17,18,21,22}$ Extremely old patients represent a small but challenging subpopulation of those with fractures of the hip, but there is little published in the way of specific outcome.

\section{Patients and Methods}

Patients aged 95 years and older presenting with a fracture of the hip were identified prospectively on presentation from the start of 2000 and were followed up until September 2004 either until their death or to the conclu- sion of the study. Follow-up information was collected from medical, general practitioner (GP) and physiotherapy/occupational therapy records and, where possible, the patients were also contacted. If a patient was unable to give the appropriate information, a family member, carer or GP was then interviewed. The data were compared that from a control cohort consisting of 200 consecutive individuals under the age of 95 who underwent similar surgery during the period of study. The control group was followed up for a period of 12 months.

All fracture types were included. In the control group four patients $(2 \%)$ sustained fractures which were subsequently histologically proven to be secondary to metastatic deposits. No patients in the study group had fractures secondary to neoplastic deposits. All had surgical treatment and followed a similar post-operative protocol with mobilisation on the first post-operative day if possible. When patients were considered fit for discharge from the trauma unit, they were transferred to either an inpatient rehabilitation ward, a nursing/residential home or their own home with the appropriate level of social support. The patients' pre-operative mobility, place of residence and health status were recorded at the time of admission. Pre- and post-operative mobility was defined by the number and type of walking aids used by the patient. Pre-operative health status was defined by the number of 
Table I. Cumulative mortality rate, length of hospital stay and pre- and post-fracture mobility status

\begin{tabular}{|c|c|c|c|}
\hline & $\begin{array}{l}\text { Number of patients } \\
\text { over } 95(\%)\end{array}$ & $\begin{array}{l}\text { Number of } \\
\text { controls (\%) }\end{array}$ & p value \\
\hline \multicolumn{4}{|l|}{ Cumulative mortality } \\
\hline 28 days & $10(20)$ & $18(9)$ & 0.005 \\
\hline 120 days & $17(34)$ & $34(17)$ & 0.001 \\
\hline 1 year & $18(36)$ & $60(30)$ & 0.229 \\
\hline \multicolumn{4}{|l|}{ Hospital stay } \\
\hline Median (range) length of acute orthopaedic ward stay (days) & $12(10$ to 14$)$ & 11 (4 to 18$)$ & 0.528 \\
\hline Median (range) length of rehabilitation ward stay (days) & $56.5(20$ to 360$)$ & $29(12$ to 102$)$ & 0.021 \\
\hline \multicolumn{4}{|l|}{ Pre-fracture mobility status } \\
\hline Fully independent & $4(8)$ & $84(42)$ & 0.001 \\
\hline Mobile with aids & $44(88)$ & $100(50)$ & 0.001 \\
\hline Mobile with assistance & $2(4)$ & $8(4)$ & 0.971 \\
\hline Bed-bound & $0(0)$ & $8(4)$ & 0.157 \\
\hline \multicolumn{4}{|l|}{ Mobility status 12 months post-fracture ${ }^{*}$} \\
\hline Fully independent & $1(3)$ & $25(18)$ & 0.035 \\
\hline Mobile with aids & $12(37)$ & $99(71)$ & 0.007 \\
\hline Mobile with assistance & $13(41)$ & $9(6)$ & 0.001 \\
\hline Bed-bound & $6(19)$ & $7(5)$ & 0.005 \\
\hline \multicolumn{4}{|l|}{ Mobility status at final follow-up } \\
\hline Fully independent & $0(0)$ & - & - \\
\hline Mobile with aids & $11(36)$ & - & - \\
\hline Mobile with assistance & $8(28)$ & - & - \\
\hline Bed-bound & $11(36)$ & - & - \\
\hline
\end{tabular}

Table II. Number of pre-existing co-morbid medical conditions, fracture type, ASA* grade and percentage of patients with active medical pathology on admission

\begin{tabular}{|c|c|c|c|}
\hline & $\begin{array}{l}\text { Number of patients } \\
\text { over } 95(\%)\end{array}$ & $\begin{array}{l}\text { Number of } \\
\text { controls }(\%)\end{array}$ & p value \\
\hline \multicolumn{4}{|l|}{ Co-morbid conditions } \\
\hline 0 & $20(40)$ & $24(12)$ & 0.001 \\
\hline 1 to 2 & $26(52)$ & $152(76)$ & 0.467 \\
\hline 3 to 4 & $4(8)$ & $24(12)$ & 0.404 \\
\hline \multicolumn{4}{|l|}{ Type of fracture } \\
\hline Intracapsular & $32(64)$ & $108(54)$ & 0.202 \\
\hline Extracapsular & $18(36)$ & $92(46)$ & 0.201 \\
\hline \multicolumn{4}{|l|}{ ASA grade } \\
\hline 1 & $0(0)$ & $8(4)$ & 0.157 \\
\hline 2 & $12(24)$ & $60(30)$ & 0.407 \\
\hline 3 & $28(56)$ & $114(57)$ & 0.877 \\
\hline 4 & $10(20)$ & $18(9)$ & 0.028 \\
\hline Active medical pathology on admission & $18(36)$ & $40(20)$ & 0.018 \\
\hline
\end{tabular}

Table III. Place of residence at the time of fracture, discharge and 12-month follow-up assessment. Values exclude those who died during the follow-up period

\begin{tabular}{|c|c|c|c|c|c|c|c|c|}
\hline \multirow[b]{2}{*}{ Place of residence } & \multicolumn{2}{|c|}{$\begin{array}{l}\text { Admission (number of } \\
\text { patients }(\%) \text { ) }\end{array}$} & \multicolumn{2}{|c|}{$\begin{array}{l}\text { Discharge destination } \\
\text { from trauma unit } \\
\text { (number of patients }(\%) \text { ) }\end{array}$} & \multicolumn{2}{|c|}{$\begin{array}{l}\text { At } 12 \text { months follow-up } \\
\text { (number of patients }(\%) \text { ) }\end{array}$} & \multicolumn{2}{|c|}{$\begin{array}{l}\text { At final follow-up } \\
\text { (number of patients }(\%) \text { ) }\end{array}$} \\
\hline & $\begin{array}{l}>95 \text { yrs } \\
(n=50)\end{array}$ & $\begin{array}{l}\text { Control } \\
(n=200)\end{array}$ & $\begin{array}{l}>95 \text { yrs } \\
(n=43)\end{array}$ & $\begin{array}{l}\text { Control } \\
(n=194)\end{array}$ & $\begin{array}{l}>95 \text { yrs } \\
(n=32)\end{array}$ & $\begin{array}{l}\text { Control } \\
(n=140)\end{array}$ & $\begin{array}{l}>95 \text { yrs } \\
(n=30)\end{array}$ & Control \\
\hline \multirow[t]{2}{*}{ Own home/sheltered housing } & $31(62)$ & $128(64)$ & $5(12)$ & $89(46)$ & $3(9)$ & $64(46)$ & $1(4)$ & - \\
\hline & $p=0.806$ & & $p=0.0001$ & & $p=0.0001$ & & & \\
\hline \multirow[t]{2}{*}{ Nursing home } & $16(32)$ & $56(28)$ & $10(23.5)$ & 37 (19) & $23(72)$ & $62(44)$ & $24(80)$ & - \\
\hline & $p=0.341$ & & $p=0.264$ & & $p=0.0001$ & & & \\
\hline \multirow[t]{2}{*}{ Hospital ward } & $3(6)$ & $16(8)$ & $28(64.5)$ & $68(35)$ & $6(19)$ & $14(10)$ & $5(16)$ & - \\
\hline & $p=0.587$ & & $p=0.001$ & & $p=0.483$ & & & \\
\hline
\end{tabular}




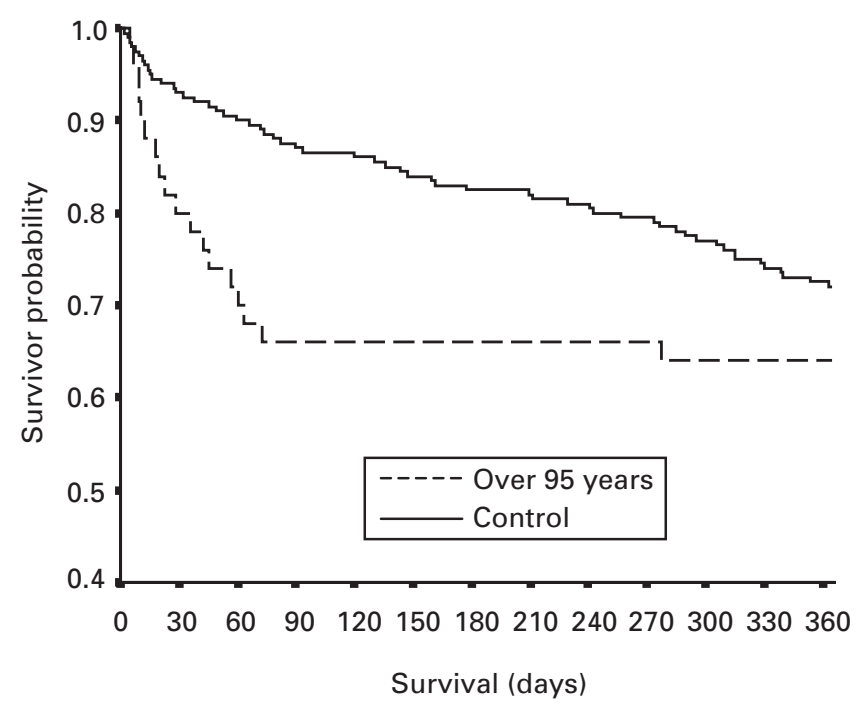

Fig. 1

Kaplan-Meier survival curve for patients aged over 95 years and control groups following surgery for fracture of the hip.
Table IV. Mortality data - females in Scotland 2000 to 2002. Source: Government Actuary's Department ${ }^{33}$

\begin{tabular}{lll}
\hline Age (yrs) & $\boldsymbol{Q x}^{*}$ & $\boldsymbol{E x}^{\dagger}$ \\
\hline 95 & 26.0 & 2.86 \\
96 & 27.1 & 2.69 \\
97 & 29.0 & 2.50 \\
98 & 31.0 & 2.32 \\
99 & 34.9 & 2.14 \\
100 & 35.1 & 2.02 \\
\hline
\end{tabular}

* $Q x$, mortality rate between age $x$ and age $x+1$ expressed as a percentage

$t E x$, average life expectancy in years from age $x$ pre-existing medical conditions including diabetes mellitus, congestive cardiac failure, cardiac arrhythmia, ischaemic heart and cerebrovascular disease, renal impairment, malignancy, Parkinson's disease, hypertension, chronic obstructive airways disease, and the need for ongoing anticoagulation therapy. These co-morbidities were chosen as important based on those reported in previous studies. ${ }^{23,24}$ It has been reported that patients with two or fewer comorbidities have improved outcomes compared to those with three or more. ${ }^{25}$ Patients were also scored at the time of surgery according to the American Society of Anesthesiologists (ASA) grading scale. ${ }^{26}$

Statistical analysis was carried out using $t$-tests for parametric data, the Mann Whitney test for non-parametric data and the chi-squared test for categorical data as appro- priate (SPSS v12.0, SPSS Inc., Chicago, Illinois). A p value of $\leq 0.05$ was considered significant. Survivorship was plotted using the Kaplan-Meier method.

\section{Results}

During the period of study 1262 patients underwent surgery for a fracture of the hip, of whom 51 (4\%) were aged 95 or more. One patient did not undergo surgery, being moribund on admission and was therefore excluded from the study. All patients were female, with a mean age of 98.1 years (95.3 to 104.9). The mean follow-up was 29.3 months (12.1 to 48.0$)$. A total of 18 patients $(36.0 \%)$ died during follow-up, with a median time to death of 14.0 days (5 to 279). The mean age of patients in the control group was 81.3 years ( 50.4 to 94.8$)$ with a female:male ratio of $4: 1$.

Survivorship following the fracture is shown for both groups in Figure 1. The cumulative mortality rate, length of stay and pre- and post-operative mobility are recorded in Table I. The number of co-morbidities, type of fracture, ASA grade and presence of associated medical pathology are shown in Table II. The place of residence prior to the fracture, at discharge and one year post-operatively are shown in Table III.

\section{Discussion}

Mortality. Many studies have attempted to identify the factors responsible for increased morbidity and mortality after fracture of the hip. Advancing age has been noted to be one such factor. 2,11,23,27-31 However, other pre-injury features, such as gender, co-morbidities and environment, have frequently acted as confounding variables in these reviews. Several authors have challenged the notion that age in isolation affects the mortality rate after fracture of the hip. 9,22 In this study, the post-operative mortality for patients aged 95 years and above was significantly higher at both 28 and 120 days $(\mathrm{p}=0.005, \mathrm{p}=0.001)$. However, by one year the mortality rate was not significantly different from that of the control population ( $\mathrm{p}=0.229)$.

In males aged 50 to 54 the annual standardised mortality rate is 6.9 per 1000 , rising to 296.6 per 1000 in those aged 95 and older. ${ }^{32,33}$ In females it rises from 4.0 per 1000 to 259.5 per 1000 , respectively. This makes direct comparison of post-operative mortality between the different age groups difficult, as it does not allow for the age-related increase in the standardised mortality rate. It is more appropriate to examine the standardised mortality rate for a particular age group.

Table IV lists data obtained from the Government Actuary's Department. It is evident that the standardised mortality rate for females in the population aged 98 years (the mean age of our study cohort) is $31.0 \%$. This is not significantly different from the one-year post-operative mortality in the study group $(p=0.445)$. In addition, the median survival from time of surgery was 2.11 years ( 5 days to 4 years). Again, this is not significantly different $(\mathrm{p}=0.275)$ 
from the mean population survival for all 98-year-old women of 2.32 years. Additionally, there was no significant difference between the mean age of survivors and those who died subsequent to surgery in the over-95 years cohort (98.1 years $v s 98.2$ years; $\mathrm{p}=0.909$ ).

Hospital stay. Several studies have reported that advancing age is associated with increased length of hospital stay after surgery for fracture of the hip. ${ }^{6,8,21}$ The mean length of stay on the acute orthopaedic unit was not significantly different between age groups. This is a consequence of the unit's transfer policy, whereby a patient would typically be moved to a rehabilitation ward if a prolonged stay was anticipated. However, when we examine the length of stay for a patient when transferred to the rehabilitation unit, this was significantly increased ( 56.5 days $v$ s 28 days; $\mathrm{p}=0.011$ ) in those patients over 95. This has obvious implications for bed occupancy and cost.

Place of residence. Where a patient resides after discharge from hospital has become an increasingly important measure of outcome owing to its effect on social function and the substantial associated cost of care in a skilled nursing facility. $6,20,34,35$ The cohort of patients admitted from home represents an important group. One of the principal aims of surgery is to return these individuals to independent living. At the time of fracture, a surprising $62 \%$ of patients aged over 95 lived independently, either in their own home or in sheltered housing. After 12 months only $12 \%$ of patients over 95 years of age were living at home, compared with $46 \%$ of the control group ( $p=0.0001$ ). By the time of final follow-up (mean 29.3 months) only $4 \%$ of patients over 95 were living independently, with the remaining $96 \%$ requiring long-term institutional care.

Walking ability. Advanced age has been cited by some investigators as being associated with a poor functional recovery after these fractures. ${ }^{19,22,23}$ At the time of fracture, $96 \%$ of patients aged 95 and over were independently mobile, mainly with the use of walking aids. However, by the final follow-up at a mean 29.3 months, only $36 \%$ were independently mobile. Of the remainder, $28 \%$ required nursing assistance with the other $36 \%$ being entirely bed bound.

Co-morbidity factors. Poorly controlled systemic illness has been associated with an increased mortality after fracture of the hip..$^{2,28,36,37}$ In this study, patients 95 years of age and over with an active medical comorbidity at the time of admission were twice as likely to die in the first postoperative year as those presenting with no active comorbidity. Kenzora et $\mathrm{al}^{9}$ found that four or more medical comorbidities significantly increased the post-operative mortality rate after fracture of the hip. In our cohort, patients with no comorbidity had a relative risk of death in the first post-operative year of 0.36 . For those with one or two comorbidities the relative risk was 1.33 , and for those with three or four the relative risk was 2.33 . None of the surviving patients had more than two medical co-morbid conditions.

\begin{tabular}{|c|c|}
\hline ASA score & Mortality \\
\hline$\overline{1^{\dagger}}$ & - \\
\hline 2 & $O(0 / 12)$ \\
\hline 3 & $29(8 / 28)$ \\
\hline 4 & $100(10 / 10)$ \\
\hline $5^{\dagger}$ & - \\
\hline
\end{tabular}

Aharanoff et $\mathrm{al}^{25}$ noted that patients undergoing surgery for fracture of the hip who are ASA 3 or 4 have a higher post-operative mortality rate than those of grades 1 and 2 . In our series, the ASA score was found to be highly predictive of post-operative mortality (Table V). These findings are also consistent with those of White et al, ${ }^{12}$ who found the ASA grading system to be the most accurate predictor of post-operative mortality after a fracture of the hip.

No benefits in any form have been received or will be received from a commercial party related directly or indirectly to the subject of this article.

\section{References}

1. Scottish Hip Fracture Audit - Report 2002. Information and Statistics Division, Edinburgh.

2. Alffram PA. An epidemiologic study of cervical and trochanteric fractures of the femur in an urban population: analysis of 1,664 cases with special reference to etiologic factors. Acta Orthop Scand 1964;26(Suppl 65):1-109.

3. DahI E. Mortality and life expectancy after hip fractures. Acta Orthop Scand 1980;51: 163-70.

4. Gordon PC. The probability of death following a fracture of the hip. Can Med Assoc J 1971;105:47-51.

5. Ions GK, Stevens J. Prediction of survival in patients with femoral neck fractures. J Bone Joint Surg [Br] 1987;69-B:384-7.

6. Jensen JS, Bagger J. Long-term social prognosis after hip fractures. Acta Orthop Scand 1982:53:97-101.

7. Jensen JS, Tondevold E. Mortality after hip fractures. Acta Orthop Scand 1979;50: 161-7.

8. Jette AM, Harris BA, Cleary PD, Campion EW. Functional recovery after hip fracture. Arch Phys Med Rehabil 1987;68:735-40.

9. Kenzora JE, McCarthy RE, Lowell JD, Sledge CB. Hip fracture mortality: relation to age, treatment, preoperative illness, time of surgery, and complications. Clin Orthop 1984;186:45-56.

10. Magaziner J, Simonsick EM, Kashner TM, Hebel JR, Kenzora JE. Survival experience of aged hip fracture patients. Am J Pub Health 1989;79:274-8.

11. Sexson SB, Lehner JT. Factors affecting hip fracture mortality. J Orthop Trauma 1987;1:298-305.

12. White BL, Fisher WD, Laurin CA. Rate of mortality for elderly patients after fracture of the hip in the 1980's. J Bone Joint Surg [Am] 1987;69-A:1335-40.

13. Meunier PJ. Prevention of hip fractures. Am J Med 1993;95(Suppl):75-8.

14. Hochberg MC, Williamson J, Skinner EA, et al. The prevalence and impact of self-reported hip fracture in elderly community-dwelling women: the women's health and aging study. Osteoporos Int 1998:8:385-9.

15. SIGN Guideline. Management of hip fracture.

16. Report of Census. 2001

17. Barangan JD. Factors that influence recovery from hip fracture during hospitalization. Orthop Nurs 1990;9:19-30.

18. Cobey JC, Cobey JH, Conant $\mathbf{L}$, et al. Indicators of recovery from fractures of the hip. Clin Orthop 1976;117:258-62. 
19. Elmerson S, Zetterberg C, Anderson GB. Ten-year survival after fractures of the proximal end of the femur. Gerontology 1988;34:186-91.

20. Gordon PC. The probability of death following a fracture of the hip. Can Med Assoc J 1971;105:47-51.

21. Magaziner J, Simonsick EM, Kashner TM, Hebel JR, Kenzora JE. Predictors of functional recovery one year following hospital discharge for hip fracture: a prospective study. J Gerontol 1990;45:101-7.

22. Mossey JM, Mutran E. Knott K, Craik R. Determinants of recovery 12 months after hip fracture: the importance of psychosocial factors. Am J Public Health 1989;79:279-86.

23. Thorngren KG. Optimal treatment of hip fractures. Acta Orthop Scand Supp/1991; 214:31-4.

24. Zuckerman JD, Skovron ML, Koval KJ, Aharanoff G, Frankel VH. Postoperative complications and mortality associated with operative delay in older patients who have a fracture of the hip. J Bone Joint Surg [Am] 1995;77-A:1551-6.

25. Aharanoff GB, Koval J, Skovron ML, Zuckerman JD. Hip fractures in the elderly: predictors of one year mortality. J Orthop Trauma 1997;11:162-5.

26. Owens WD, Felts JA, Spitznagel EL Jr. ASA physical status classifications: a study of consistency ratings. Anesthesiology 1978;49:239-43.

27. el Banna S, Raynal L, Gerebtzof A. Fractures of the hip in the elderly: therapeutic and medico-social considerations. Arch Gerontol Geriat 1984;3:311-19.

28. Gordon C. The probability of death following a fracture of the hip. Can Med Assoc $J$ 1971;105:47-51.
29. Holmberg S, Conradi P, Kalen R, Thorngren KG. Mortality after cervical hip fracture: 3002 patients followed for 6 years. Acta Orthop Scand 1986;57:8-11.

30. Johnson JT, Crothers $\mathbf{0}$. Nailing versus prosthesis for femoral-neck fractures: a critical review of long-term results in two hundred and thirty-nine consecutive private patients. J Bone Joint Surg [Am] 1975;57-A:686-92

31. Miller CW. Survival and ambulation following hip fracture. J Bone Joint Surg [Am] 1978;60-A:930-4

32. Review of Registrar General on deaths in England and Wales, 1998. Series $\mathrm{DH} 1$, No. 31.

33. Interim Life Tables. Expectation of Life. Males and females in Scotland. Report 2000-2002. Government Actuary's Department.

34. Broos PL, Stappaerts KH, Luiten EJ, Gruwez JA. Home-going: prognostic factors concerning the major goal in treatment of elderly hip fracture-patients. Int Surg 1988; 73:148-50.

35. Barangan JD. Factors that influence recovery from hip fracture during hospitalization. Orthop Nurs 1990;9:19-30.

36. Fitzgerald JF, Moore PS, Dittus RS. The care of elderly patients with hip fracture: changes since implementation of the prospective payment system. N Engl J Med 1988;319:1392-7.

37. Fitzgerald JF, Fagan LF, Tierny WM, Dittus RS. Changing patterns of hip fracture care before and after implementation of the prospective payment system. JAMA 1987;258:218-21. 